\title{
FINITE ELEMENT DYNAMIC ANALYSIS OF NON-UNIFORM BEAMS ON VARIABLE ONE-PARAMETER FOUNDATION SUBJECTED TO UNIFORMLY DISTRIBUTED MOVING LOADS
}

\author{
I.O. ABIALA* \\ Department of Mathematics, University of Lagos \\ Akoka, Lagos, NIGERIA \\ E-mail: iabiala@unilag.edu.ng \\ J.A. GBADEYAN \\ Department of Mathematics, University of Ilorin \\ Ilorin, NIGERIA
}

\begin{abstract}
A general numerical analysis theory capable of describing the behaviour of a non-uniform beam resting on variable one parameter (Winkler) foundation under a uniform partially distributed moving load is developed. The versatile numerical solution technique employed is based on the finite element and Newmark integration methods. The analysis is carried out in order to evaluate the effect of the following parameters (i) the speed of the moving load (ii) the span length of the beam (iii) two types of vibrating configurations of the beam (iv) the load's length and (v) the elastic foundation modulus, on the dynamic behaviour of the non-uniform beam resting on the variable one-parameter foundation. Numerical examples which showed that the above parameters have significant effects on the dynamic behaviour of the moving load problem are presented.
\end{abstract}

Key words: finite element, dynamic analysis, non-uniform beams, one-parameter foundation.

\section{Introduction}

It is well known that static loads (forces) are functions of the spatial variables only, while dynamic loads are functions of time as well as the spatial variables. However, dynamic loads which are, in addition, continuously changing their positions are known as moving loads. Examples include trains, cars, trucks, cranes, and pedestrians walking or running across bridges. Moving loads usually cause elastic structures, such as beams, on which they act to vibrate intensively particularly when high velocities are involved. The problem of accessing the response of elastic structures to moving loads known as the moving load problem, is of technological importance. For instance, elastic structures are commonly used in the design of aircrafts which are under the influence of various types of moving pressure loads during flight (Chonany, 1984). Hence, the problem of analysing the dynamic response of elastic structures under the action of moving loads continues to motivate a variety of investigations (Stokes, 1883). Such investigations are found in civil, mechanical, transport, astronautical and marine engineering as well as, applied mathematics, since moving loads are present in all these fields (Fryba, 1973). Significant early contributions towards solving various types of moving loads problems were made by Wills (1849), Stokes (1883), Zimmermann (1896), Krylov (1971), Timoshenko et al. (1974), Lowan (1935), Bolotin (1961), Inglis (1934), Hillerborg (1951) and Kolousek (1974). Later an extended review on this subject was carried out by Fryba (1973) in his excellent monograph. The dynamic response of a simply supported beam traversed by a concentrated moving load was determined by Stanisic and Hardin (1968). They developed an interesting technique which, however, cannot

\footnotetext{
* To whom correspondence should be addressed
} 
easily be applied to various boundary conditions which are of practical interest. Akin and Mofid (1989) presented an analytic-numerical method that can be used to determine the dynamic behaviour of beams carrying a concentrated moving mass. The problem of dynamic behaviour of an elastic beam subjected to a moving concentrated mass was also studied by Sadiku and Leipholz (1995). Gbadeyan and Oni (1995) presented a more versatile technique which can be used to determine the dynamic behaviour of beams having arbitrary end supports. Michaltos et al. (1996) studied the effect of the mass of a moving load on the dynamic response of a simply supported beam. A detailed analysis of the effect of centripetal and Coriolis forces on the dynamic response of light (steel) bridges under moving loads was also carried out by Michaltos and Kounadis (2001). It is remarked at this junctures, that the elastic parameters of the beams in all the work discussed hitherto, are assumed constants. In other words, uniform beams were considered. The reason for this is not far fetched since by making such an assumption, the various researchers ended up with the governing partial differential equations having constant coefficients only and thereby based the aforementioned investigations, in general, on analytical approaches. Otherwise, the researchers could have found it very difficult, if not impossible, to obtain analytical closed form solutions to the problems. However, practical structures for which the elastic properties are functions of spatial coordinates abound. Hence in this paper, beams that are not uniform are considered.

Some of the previous works involving non-uniform beams include that of Wu and Dai (1987). They studied the dynamic responses of multi-span non-uniform beams under moving loads using the transfer matrix method. Dugush and Eisenberger (2002) also investigated the dynamic behaviour of multi-span nonuniform beams traversed by a moving load at constant and variable velocities. They used both modal analysis and direct methods. The analysis of a variable cross-section beam subjected to a moving concentrated force and mass is investigated in Ahmadian et al. (2006) using the finite element method.

Although, the above completed works on both uniform and non-uniform beams are impressive, only concentrated moving loads were considered. However, such loads do not represent the physical reality of the problem formulation. As a matter of fact, concentrated loads do not exist physically. For practical applications, it is realistic to consider the moving loads as distributed moving loads as opposed to concentrated moving loads. Hence, the present paper deals with the more realistic moving load, namely, a uniform partially distributed moving load. The first work on moving loads, to the best knowledge of the authors, to consider distributed moving loads was that of Esmailzadeh and Ghorashi (1995). The work in Esmailzadeh and Ghorashi (1995) was extended by the same authors (Esmailzadeh and Ghorashi, 1997) to include the vibration of a Timoshenko beam. In Gbadeyan et al. (2002), the vibration analysis of beams traversed by distributed moving masses was studied. Dada (2003) investigated the transverse vibration of beams on an elastic foundation subjected to distributed moving masses. Gbadeyan and Dada (2007) also studied, recently, the effect of a linearly varying distributed moving load on beams. Most recently, Akpobi and Nkenwokeneme (2009) attempted to carry out the analysis of the transverse vibration of beams under a moving load using the finite element eigenvector method. However, both the analysis and the illustrative example discussed do not involve a moving load. In other words, unlike Dada's work (2003) their work has nothing to do with mobile distributed masses. The problem of determining the dynamic behaviour of viscoelastically connected beams under a moving distributed load was studied in Gbadeyan and Dada (2007). We also remark, at this juncture, that only uniform beams were considered in all these previous works involving distributed moving loads.

In the context discussed so far, this paper, therefore, focuses on determining the dynamic behaviour of a non-uniform Euler-Bernoulli beam resting continuously on a variable Winkler foundation and traversed by a uniform partially distributed moving load. Specifically, the elastic properties of the beam such as the flexural rigidity, the mass density per unit length of the beam, as well as, the elastic foundation modulus parameter which are usually assumed constants are hereby expressed as functions of the spatial variables. The dynamic responses of the non-uniform beams subjected to uniformly distributed moving loads were then analysed using the finite element technique. Firstly, the non-uniform continuous beam was replaced by a non-continuous (discrete) system made up of beam elements. The modified elemental and overall stiffness and mass matrices, the elemental and overall centripetal acceleration matrices as well as the elemental and overall load vectors were then derived. Next, Newmark's integration method was used to obtain the desired 
response of the non-uniform beam with elastic foundation. The key points of interest in this paper were to evaluate the effect of the following parameters: (i) the speed of the moving load; (ii) different boundary conditions of the vibrating beams; (iii) the span length of the beam; (iv) the load's length and; (v) the elastic modulus of the foundation, on the dynamic behaviour of the non-uniform beam with foundation. The effects of shear deformation, rotatory inertia and damping are assumed negligible.

\section{Further assumptions and the initial boundary-value problem}

The dynamic behaviour of simply supported non-uniform elastic beam resting on a variable Winkler foundation and traversed by a uniform partially distributed moving mass is governed by an initial boundary value system of equations. This system of equations is made up of, firstly, the following fourth order partial differential equation

$$
\begin{aligned}
& \frac{\partial^{2}}{\partial x^{2}}\left(E I(x) \frac{\partial^{2} V(x, t)}{\partial x^{2}}\right)+\rho A(x) \frac{\partial^{2} V(x, t)}{\partial x^{2}} \\
& +F R(x, t)=Q(x, t)
\end{aligned}
$$

where the flexural rigidity, $E I(x)$, of the beam and the cross section area, $A(x)$, of the beam are assumed not constant but varying with respect to the spatial coordinates $x$ as follows (Dogush and Eisenberger, 2002; Abiala, 2008)

and

$$
E I(x)=\sum_{r=1}^{\text {noofspan }} E I_{r}\left(x-\sum_{l=1}^{r-1} l_{l}\right)\left[\begin{array}{c}
H\left(x-\sum_{l=1}^{r-1} l_{l}\right) \\
-H\left(x-\sum_{l=1}^{r-1} l_{l}\right)
\end{array}\right]
$$

$$
A(x)=\sum_{r=1}^{\text {noofspan }} A_{r}\left(x-\sum_{l=1}^{r-1} l_{l}\right)\left[\begin{array}{c}
H\left(x-\sum_{l=1}^{r-1} l_{l}\right) \\
-H\left(x-\sum_{l=1}^{r-1} l_{l}\right)
\end{array}\right]
$$

respectively, $V(x, t)$ is the transverse deflection of the beam, $\rho$ the constant density per unit length of the beam, $t$ the time, $Q(x, t)$ is the externally applied moving load. $F R(x, t)$ is the foundation reaction (pressure) and $H(x)$ the Heavyside function.

It is assumed that the foundation material covers the whole length of the beam and that there are no shearing forces at the contacting surface. The implication of this is that the (radiation) foundation damping is negligible and the foundation reaction is related to the transverse deflection $V(x, t)$ as follows $[28,29]$ :

$$
F R(x, t)=K(x) V(x, t)+m_{f} \frac{\partial^{2} V(x, t)}{\partial t^{2}}
$$

where the foundation stiffness function $K(x)$, is defined as 


$$
K(x)=k\left(4 x-3 x^{2}+x^{3}\right)
$$

while $K$ is the foundation modulus parameter, $m_{f}$ is the mass of the foundation and $\mathrm{k}$ is an arbitrary constant. It is furthermore assumed that the load moves at a constant velocity $\left(u_{l}\right)$, keeps contact with the beam continually before arriving at the other end support and it is uniform partially distributed. Hence, taking also into cognizance both the gravitational and inertial forces of the load, the externally applied moving load $Q(x, t)$ is defined as

$$
\begin{aligned}
& Q(x, t)=\frac{l}{\varepsilon}\left[-m_{l} g-m_{l}\left(\frac{\partial^{2} V(x, t)}{\partial t^{2}}+2 u_{l} \frac{\partial^{2} V(x, t)}{\partial x \partial t}+\right.\right. \\
& \left.\left.+u_{l}^{2} \frac{\partial^{2} V(x, t)}{\partial x^{2}}\right)\right]\left(H\left(x-\xi+\frac{\varepsilon}{2}\right)-H\left(x-\xi-\frac{\varepsilon}{2}\right)\right)
\end{aligned}
$$

where $m_{l}$ is the mass of the moving load, $g$ is the acceleration due to gravity, $\varepsilon$ is the load's length and $\xi$ is the distance covered by the moving load.

For the simply supported non uniform beam of the span $l$, the boundary conditions may be described mathematically as follows

$$
\begin{aligned}
& V(0, t)=V(l, t)=0, \\
& \frac{\partial^{2} V}{\partial x^{2}}(x, t)_{x=0}=\frac{\partial^{2} V}{\partial x^{2}}(x, t)_{x=l}=0 .
\end{aligned}
$$
are given as

On the other hand, the boundary conditions for an elastic non- uniform beam clamped at both ends

$$
\begin{aligned}
& V(0, t)=V(l, t)=0 \\
& \frac{\partial^{2} V}{\partial x^{2}}(x, t)_{x=0}=\frac{\partial^{2} V}{\partial x^{2}}(x, t)_{x=l} \neq 0
\end{aligned}
$$

The non- uniform beam is considered to be initially at rest, hence, the corresponding initial conditions are

$$
V(x, 0)=\left.\frac{\partial V(x, o)}{\partial t}\right|_{x=l}=0
$$

Equation (2.1) with Eqs (2.2), (2.6), (2.7) or (2.8)) and (2.9) constitute the initial - boundary- value problem. The closed - form solutions of the problem is either impossible or very difficult to obtain using an analytical approach, hence in what follows we employ the finite element method.

\section{The finite element formulation of the moving load problem}

The finite element technique assumes that the unknown transverse deflection of the non-uniform beam, $V(x, t)$, can be represented approximately by a set of piecewise continuous functions which are defined over a finite number of sub-regions called elements and composed of the numerical values of the 
unknown deflection within the region. Thus the first step, involved in the technique, consists of dividing the spatial solution domain of the non - uniform beam, which happens to be the length of the beam in this case, into a number of sub domains known as finite elements. These elements are joined to each other at selected points called nodes.

Next, the weak or variational form of the governing Eq.(2.1) is constructed as follows:

Consider a typical element of length $l$ so that its domain $\Omega_{e}$ is such that $\Omega_{e}=(o, l)$. Substituting, Eqs (2.4) and (2.6) into (2.1) we have

$$
\begin{aligned}
& \frac{\partial^{2} V}{\partial x^{2}}\left(E I(x) \frac{\partial^{2} V(x, t)}{\partial x^{2}}\right)+\rho A(x) \frac{\partial^{2} V(x, t)}{\partial t^{2}}+m_{f} \frac{\partial^{2} V(x, t)}{\partial t^{2}}+K(x) V(x, t)= \\
& =\frac{1}{\varepsilon}\left[-m_{l} g-m_{l}\left(\frac{\partial^{2} V(x, t)}{\partial t^{2}}+2 u_{l} \frac{\partial^{2} V(x, t)}{\partial x \partial t}+u_{l}^{2} \frac{\partial^{2} V(x, t)}{\partial x^{2}}\right)\right]\left(H\left(x-\xi+\frac{\varepsilon}{2}\right)-H\left(x-\xi-\frac{\varepsilon}{2}\right)\right) .
\end{aligned}
$$

Let $G(x)$ be Galerkin's weight or test function. Multiplying Eq.(3.1) by $G(x)$ and integrating over the domain $\Omega_{e}$, we obtain

$$
\begin{aligned}
& \int_{0}^{L^{e}}\left\{\frac{\partial^{2}}{\partial x^{2}}\left(E I(x) \frac{\partial^{2} V(x, t)}{\partial x^{2}}\right)+\rho A(x) \frac{\partial^{2} V(x, t)}{\partial t^{2}}+m_{f} \frac{\partial^{2} V(x, t)}{\partial t^{2}}+K(x) V(x, t)+\right. \\
& -\frac{1}{\varepsilon}\left[-m_{\mathrm{\imath}} g-m_{\mathrm{\imath}}\left(\frac{\partial^{2} V(x, t)}{\partial t^{2}}+2 u_{\mathrm{\imath}} \frac{\partial^{2} V(x, t)}{\partial x^{2}}+u_{\mathrm{\imath}}{ }^{2} \frac{\partial^{2} V(x, t)}{\partial x^{2}}\right)\right] \times \\
& \times\left[H\left(x-\xi+\frac{\varepsilon}{2}\right)-H\left(\left(x-\xi-\frac{\varepsilon}{2}\right)\right]\right\} G(x) d x=0 .
\end{aligned}
$$

Integrating twice the first term on the left hand side of Eq.(3.1) by parts, rearranging and using the prescribed boundary conditions (say, Eq.(2.7)), we obtain

$$
\begin{aligned}
& \int_{o}^{l^{e}} E I(x) \frac{\partial^{2} V(x, t)}{\partial x^{2}} \frac{\partial^{2} G(x)}{\partial x^{2}} d x+Q_{\mathrm{l}}^{e}+\int_{o}^{l^{e}}\left(\rho A(x)+m_{f}\right) \frac{\partial^{2} V(x, t)}{\partial t^{2}} G(x) d x+ \\
& +\int_{o}^{l^{e}} K(x) V(x, t) G(x) \partial x=-m_{l} g / \varepsilon \int_{0}^{l^{e}} G(x) \times\left[H\left(x-\xi+\frac{\varepsilon}{2}\right)-H\left(x-\xi-\frac{\varepsilon}{2}\right)\right] d x+ \\
& -m_{l} / \varepsilon \int_{o}^{l^{e}} \frac{\partial^{2} V(x, t)}{\partial t^{2}} G(x)\left[H\left(x-\xi+\frac{\varepsilon}{2}\right)+H\left(x-\xi-\frac{\varepsilon}{2}\right)\right] d x-2 m_{\mathrm{\imath}} u_{\mathrm{l}} / \varepsilon \int_{o}^{l^{e}} \frac{\partial^{2} V(x, t)}{\partial x^{2}} \\
& G(x)\left[H\left(x-\xi+\frac{\varepsilon}{2}\right)-H\left(x-\xi-\frac{\varepsilon}{2}\right)\right] d x-m_{\mathrm{\imath}} u_{\mathrm{l}}^{2} / \varepsilon \int_{o}^{l^{e}} \frac{\partial^{2} V(x, t)}{\partial x^{2}} G(x)\left[H\left(x-\xi+\frac{\varepsilon}{2}\right)+\right. \\
& -H(x-\xi-\varepsilon / 2)]
\end{aligned}
$$


where

$$
\begin{aligned}
& Q_{L}^{e}=\left.[\phi G(x)]\right|_{o} ^{l^{e}}-\left.\left[\varphi \frac{\partial G(x)}{\partial x}\right]\right|_{o} ^{l^{e}}, \\
& \phi=\frac{\partial}{\partial x}\left[E I(x) \frac{\partial V^{2}(x, t)}{\partial x^{2}}\right], \text { the shear force, } \\
& \varphi=E I(x)\left(\frac{\partial^{2} V(x, t)}{\partial x^{2}}\right), \text { the bending moment. }
\end{aligned}
$$

It is remarked that Eq.(3.3) consists of the boundary terms. They are essentially four terms, two at each of the end nodes of the element. As a matter of fact, there exist two natural boundary conditions (viz: $\varphi$ and $\phi)$ being specified at one of the end nodes and two essential boundary conditions (viz, $V(x, t)$ and $\left.\frac{\partial}{\partial x} V(x, t)\right)$ being specified at the other end node.

Now suppose

$$
\begin{array}{ll}
Q_{1}^{e}=\left.\left[\frac{\partial}{\partial x}\left(E I(x) \frac{\partial^{2} V(x, t)}{\partial x^{2}}\right)\right]\right|_{x=0} ; & Q_{2}^{e}=\left.\frac{\partial^{2} V(x, t)}{\partial x^{2}}\right|_{x=0}, \\
Q_{3}^{e}=-\left.\left[\frac{\partial}{\partial x}\left(E I(x) \frac{\partial^{2} V(x, t)}{\partial x^{2}}\right)\right]\right|_{x=l^{e}} ; & Q_{4}^{e}=\left.E I(x) \frac{\partial^{2} V(x, t)}{\partial x^{2}}\right|_{x=l^{e}} .
\end{array}
$$

In view of Eqs (3.4), Eq.(3.3) becomes

$$
\begin{aligned}
& \int_{0}^{l^{e}} E I(x) \frac{\partial^{2} V(x, t)}{\partial x^{2}} \frac{\partial^{2} G(x)}{\partial x^{2}} d x+\int_{0}^{l}\left(\rho A(x)+m_{f}\right) \frac{\partial^{2} V(x, t)}{\partial t^{2}} G(x) d x+ \\
& +\int_{0}^{l^{e}} K(x) V(x, t) G(x) d x \\
& +m_{\mathrm{l}} g / \varepsilon \int_{0}^{l^{e}} G(x)[H(x-\xi+\varepsilon / 2)-H(x-\xi-\varepsilon / 2)] d x+ \\
& m_{\mathrm{l}} / \varepsilon \int_{0}^{l^{e}} \frac{\partial^{2} V(x, t)}{\partial x^{2}} G(x)[H(x-\xi+\varepsilon / 2)-H(x-\xi-\varepsilon / 2)] d x+ \\
& +2 m_{\mathrm{l}} u_{\mathrm{l}}^{2} / \varepsilon \int_{0}^{l^{e}} \frac{\partial^{2} V(x, t)}{\partial x^{2}} G(x)[H(x-\xi+\varepsilon / 2)-H(x-\xi-\varepsilon / 2)] d x+ \\
& \left.+m_{l} u^{2}{ }_{l} / \int_{0}^{l^{e}} \frac{\partial^{2} V(x, t)}{\partial x^{2}}\right) G(x)[H(x-\xi+\varepsilon / 2)-H(x-\xi-\varepsilon / 2)] d x+ \\
& -G\left(l^{e}\right) Q_{3}^{e}-G(0) G_{1}^{e}+\left.\frac{\partial G}{\partial x}\right|_{x=L^{e}} Q_{4}^{e}+\left.\frac{\partial G}{\partial x}\right|_{x-0} Q_{2}^{e}=0 .
\end{aligned}
$$


However, it can be easily shown that (Dada, 2003)

$$
\int_{0}^{l^{e}} f(x)[H(x-\xi+\varepsilon / 2)-H(x-\xi-\varepsilon / 2)] d x=\int_{\xi-\epsilon / 2}^{\xi+\epsilon / 2} f(x) d x .
$$

Hence, Eq.(3.5) reduces to

$$
\begin{aligned}
& \int_{0}^{l^{e}} E I(x) \frac{\partial^{2} V(x, t)}{\partial x^{2}} \frac{\partial^{2}}{\partial x^{2}} G(x) d x+\int_{0}^{l^{e}}\left(\rho A(x)+m_{f}\right) \frac{\partial^{2} V(x, t)}{\partial x^{2}} G(x) d x+\int_{0}^{l^{e}} K(x) V(x, t) G(x) d x= \\
& =-m g / \varepsilon \int_{\xi-\varepsilon / 2}^{\xi+\varepsilon / 2} G(x) d x-m_{1} / \varepsilon \int_{\xi-\varepsilon / 2}^{\xi+\varepsilon / 2} \frac{\partial^{2} V(x, t) G(x) d x}{\partial t^{2}}-2 m_{1} u_{1} / \varepsilon \int_{\xi-\varepsilon / 2}^{\xi+\varepsilon / 2} \frac{\partial^{2} V(x, t) G(x) d x}{\partial x \partial t}+ \\
& -m_{1} u_{1}^{2} / \varepsilon \int_{\xi-\varepsilon / 2}^{\xi+\varepsilon / 2} \frac{\partial^{2} V(x, t) G(x) d x}{\partial x^{2}}\left|x=l^{e}+G\left(l^{e}\right) Q_{3}^{e}+G(0) Q_{1}^{e}-\frac{\partial G(x)}{\partial x}\right| x=l^{e} Q_{4}^{e}-\frac{\partial G(x)}{\partial x} \mid x=0 Q_{2}^{e} .
\end{aligned}
$$

Equation (3.7) is the desired weak or variational form of the moving load problem involving the nonuniform beam resting on variable one-parameter foundation.

Having constructed the weak form of the moving load problem we next seek an approximate solution over the element under consideration and thereby construct the corresponding shape functions. To this end , it is assumed that the unknown deflection $V(x, t)$ could be expressed approximately as

$$
\begin{aligned}
& V(x, t) \approx V_{n}(x, t)=H_{1}(x) V_{1}(t)+H_{2}(x) V_{2}(t)+H_{3}(x) V_{3}(t)+H_{4}(x) V_{4}(t)= \\
& =\sum_{k=1}^{4} H_{k}(x) V_{k}(t)=\{H\}\{Y(t)\}
\end{aligned}
$$

where $H_{k}(x), k=1,2,3,4$ are called Hermite cubic shape functions, $V_{k}(t), k=1,2,3,4$ are the modal deflection functions and $H$ is the row vector

$$
[H]=\left[H_{1}(x), H_{2}(x), H_{3}(x), H_{4}(x)\right] .
$$

The three procedures involved in constructing the four shape functions are explained in detail in Abiala (2008). For brevity, it suffices to state that they are of the form

$$
\begin{array}{ll}
H_{1}=l-\frac{3 h^{2}}{l^{2}}+\frac{2 h^{3}}{l^{3}}, & H_{3}=\frac{3 h^{2}}{l^{2}}-\frac{2 h^{3}}{l^{3}}, \\
H_{2}=h-\frac{2 h^{2}}{l}+\frac{h^{3}}{l^{2}}, & H_{4}=-\frac{h^{2}}{l}+\frac{h^{3}}{l^{2}}
\end{array}
$$

where $h$ is the spatial coordinate.

Now substituting Eq.(3.9) into the weak form Eq.(3.7) and replacing the weight function $G(x)$ therein by the shape function, we obtain 


$$
\begin{aligned}
& \sum_{k=1}^{4}\left\{\int_{0}^{L^{e}} E I(x) \frac{\partial^{2} H_{1}}{\partial x^{2}} \frac{\partial^{2}}{\partial x^{2}}[H k(x) V k(x)] d x+\int_{0}^{L^{e}}(\rho A(x)+m) H_{1}(x) \frac{\partial^{2}}{\partial t^{2}}[H k(x) V k(x)] d x+\right. \\
& +\int_{0}^{L^{e}} K(x) H k(x) V k(t) H 1(x) d x+\frac{m 1}{\varepsilon} \int_{\xi-\varepsilon / 2}^{\xi+\varepsilon / 2} H 1(x) \frac{\partial^{2}}{\partial t^{2}}[H k(x) V k(t)] d x+ \\
& +\frac{2 m I u 1}{\varepsilon} \int_{\xi-\varepsilon / 2}^{\xi+\varepsilon / 2} H 1(x) \frac{\partial^{2}}{\partial x \partial t}[H k(x) V k(t)] d x+\frac{m l u 12}{\varepsilon} E 1(x)\left(\frac{\partial^{2}}{\partial x^{2}}[H k(x) V k(t)]\right) \mid x= \\
& \left.=0 E 1(x) \frac{\partial^{2}}{\partial x^{2}}[H k(x) V k(t)] \mid x=0\right\}+\frac{m g}{\varepsilon} \int_{\xi-\varepsilon / 2}^{\xi+\varepsilon / 2} H 1(x) d x=0 .
\end{aligned}
$$

Setting

$$
\begin{aligned}
& K_{I k}^{*}=\int_{0}^{l^{e}} E I(x) H_{K}^{11}(x) H_{1}^{11} d x \\
& K_{I K}^{*}=\int_{0}^{l^{e}} k(x) H_{k}(x) H_{l}(x) d x k_{! k}^{* *}=m_{L} u_{L}^{2} \int_{\xi-\xi / 2}^{\xi+\xi / 2} H_{l}(x) \frac{\partial^{2}}{\partial x^{2}} H_{k}(x) d x \text {, } \\
& M_{I k}^{*}=\int_{0}^{l^{e}}\left(\rho A(x)+m_{F}\right) H_{l}(x) H_{k} d x ; \quad M_{l k}^{* *}=m_{L} / \in \int_{\xi-\xi / 2}^{\xi+\xi / 2} H_{l}(x) H_{k}(x) d x, \\
& C \frac{m_{L} u_{L}}{\epsilon} \int_{\xi-\xi / 2}^{\xi+\xi / 2} H_{l}(x) \frac{\partial}{\partial x} H_{k}(x) d x ; \quad f_{l}=\frac{m_{L} g}{\epsilon} \int_{\xi-\xi / 2}^{\xi+\xi / 2} H_{l}(x) d x, \quad \text { and } \\
& Q_{l}=-\left.H_{l}\left(l^{e}\right) \frac{\partial^{2}}{\partial x^{2}}\left(E I(x) \frac{\partial^{2}}{\partial x^{2}}\left[H_{K}(x) V_{k}(t)\right]\right)\right|_{x=l^{e}}+ \\
& -\left.H_{l}\left(l^{e}\right) \frac{\partial}{\partial x}\left(E I(x) \frac{\partial^{2}}{\partial x^{2}}\left[H_{K}(x) V_{k}(t)\right]\right)\right|_{x=0}+ \\
& +\left.\left.\frac{\partial H_{l}(x)}{\partial x}\right|_{x=l^{e}}\left(E I(x) \frac{\partial^{2}}{\partial x^{2}}\left[H_{K}(x) V_{k}(t)\right]\right)\right|_{x=l^{e}}+ \\
& +\left.\left.\frac{\partial H_{l}(x)}{\partial x}\right|_{x=0}\left(E I(x) \frac{\partial^{2}}{\partial x^{2}}\left[H_{K}(x) V_{k}(t)\right]\right)\right|_{x=0}
\end{aligned}
$$

where (") denotes second derivatives with respect to $x$, Eq.(3.10) becomes 


$$
\begin{aligned}
& \sum_{k=1}^{4} k_{I k}^{*} V_{k}^{t}+\sum_{k=1}^{4} k_{I k}^{*} \ddot{V}_{k}(t)+\sum_{k=1}^{4} k_{I k}^{* *} \ddot{V}_{k}(t)+\sum_{k=1}^{4} C_{I k} \dot{V}_{k}(t)+ \\
& \sum_{k=1}^{4} k_{I k}^{* * *} V_{k}(t)+\sum_{k=1}^{4} k_{I k}^{* *} V_{k}(t)+f_{I}+Q_{l}=0 .
\end{aligned}
$$

Equation (3.12) implies

$$
\begin{aligned}
& K_{11}^{e} V_{1}(t)+K_{12}^{e} V_{2}(t)+K_{13}^{e} V_{3}(t)+K_{14}^{e} V_{4}(t)+M_{11}^{e} V_{1}(t)+M_{12}^{e} V_{2}(t)+M_{13}^{e} V_{3}(t)+ \\
& +M_{14}^{e} V_{4}(t)+C_{11}^{e} V_{1}(t)+C_{12}^{e} V_{2}(t)+C_{13}^{e} V_{3}(t)+C_{14}^{e} V_{4}(t)+f_{11}^{e} Q_{1}^{e}(t)=0
\end{aligned}
$$

where

$$
\begin{aligned}
& K_{I j}^{e}=K_{I j}^{*}+K_{I j}^{* *}+K_{I j}^{* * *} \quad j=1,2,3,4, \\
& M_{I j}^{e}=M_{I j}^{*}+M_{I j}^{* *} .
\end{aligned}
$$

Using arguments similar to those for $G(x)=H(x)$ we have:

For $G(x)=H_{2}(x)$

$$
\begin{aligned}
& \sum_{k=1}^{4} k_{2 k}^{*} V_{k}(t)+\sum_{k=1}^{4} k_{2 k}^{* *} V_{k}(k)+\sum_{k=1}^{4} M_{2 k}^{*} V(t)+\sum_{k=1}^{4} M_{2 k}^{* *} V_{k}(t)+ \\
& +\sum_{k=1}^{4} C_{2 k}^{* *} V_{k}(t)+\sum_{k=1}^{4} k_{2 k}^{* *} V_{k}(k)+f_{2}+Q_{2}=0 .
\end{aligned}
$$

For $G(x)=H_{3}(x)$

$$
\begin{aligned}
& \sum_{k=1}^{4} k_{3 k}^{*} V_{k}(t)+\sum_{k=1}^{4} k_{3 k}^{* *} V_{k}(k)+\sum_{k=1}^{4} M_{3 k}^{*} V(t)+\sum_{k=1}^{4} M_{3 k}^{* *} V_{k}(t)+ \\
& +\sum_{k=1}^{4} C_{3 k}^{* *} V_{k}(t)+\sum_{k=1}^{4} k_{3 k}^{* *} V_{k}(k)+f_{3}+Q_{3}=0 .
\end{aligned}
$$

For $G(x)=H_{4}(x)$

$$
\begin{aligned}
& \sum_{k=1}^{4} k_{4 k}^{*} V_{k}(t)+\sum_{k=1}^{4} k_{4 k}^{* *} V_{k}(k)+\sum_{k=1}^{4} M_{4 k}^{*} V(t)+\sum_{k=1}^{4} M_{4 k}^{* *} V_{k}(t)+ \\
& +\sum_{k=1}^{4} C_{4 k}^{* *} V_{k}(t)+\sum_{k=1}^{4} k_{4 k}^{* *} V_{k}(k)+f_{4}+Q_{4}=0 .
\end{aligned}
$$

Also, each of Eqs (3.16a) - (3.16c) implies 


$$
\begin{aligned}
& k_{p k}^{*}=\int_{0}^{l e} E I(x) H_{k}^{l 1}(x) H_{P_{2}}^{11}(x) d x, k_{p k}^{* *}=\int_{0}^{l e} k(x) H_{k}(x) H_{P}(x) d x, \\
& k_{P k}^{* *}=\frac{m_{l} u_{l}^{2}}{\int_{\xi-\xi}^{\xi} \xi \xi / 2} H_{P}(x) \frac{\partial^{2} H_{k}(x)}{\partial x^{2}} d x
\end{aligned}
$$

Such that

$$
\begin{aligned}
& k_{21}^{e} V_{1}(t)+k_{22}^{e} V_{2}(t)+k_{23}^{e} V_{3}(t)+k_{24}^{e} V_{4}(t)+M_{21}^{e} V_{1}(t)+M_{22}^{e} V_{2}(t)+M_{23}^{e} V_{3}(t)+M_{24}^{e} V_{4}+ \\
& +C_{21}^{e} V_{1}(t)+C_{22}^{e} V_{2}(t)+C_{23}^{e} V_{3}(t)+C_{24}^{e} V_{4}(t)+Q_{2}^{e}+f_{2}^{e}=0 . \\
& k_{31}^{e} V_{1}(t)+k_{32}^{e} V_{2}(t)+k_{33}^{e} V_{3}(t)+k_{34}^{e} V_{4}(t)+M_{31}^{e} V_{1}(t)+M_{32}^{e} V_{2}(t)+M_{33}^{e} V_{3}(t)+M_{34}^{e} V_{4}+ \\
& +C_{31}^{e} V_{1}(t)+C_{32}^{e} V_{2}(t)+C_{33}^{e} V_{3}(t)+C_{34}^{e} V_{4}(t)+Q_{3}^{e}+f_{3}^{e}=0, \\
& k_{41}^{e} V_{1}(t)+k_{42}^{e} V_{2}(t)+k_{43}^{e} V_{3}(t)+k_{44}^{e} V_{4}(t)+M_{41}^{e} V_{1}(t)+M_{42}^{e} V_{2}(t)+M_{43}^{e} V_{3}(t)+M_{44}^{e} V_{4}+ \\
& +C_{41}^{e} V_{1}(t)+C_{42}^{e} V_{2}(t)+C_{43}^{e} V_{3}(t)+C_{44}^{e} V_{4}(t)+Q_{4}^{e}+f_{4}^{e}=0,
\end{aligned}
$$

and

$$
\begin{aligned}
& k_{i j}^{e}=k_{i j}^{*}+k_{i j}^{* *}+k_{i j}^{* * *}, \\
& M_{i j}^{e}=M_{i j}^{*}+M_{i j}^{* *}+M_{i j}^{* * * *}, \quad i=2,3,4, \quad j=1,2,3,4 .
\end{aligned}
$$

At this juncture, it should be noted that Eqs (3.13), (3.17a), (3.17b) and (3.17c) can be written as matrix form as follows

$$
\begin{aligned}
& {\left[\begin{array}{llll}
k_{11}^{e} & k_{12}^{e} & k_{13}^{e} & k_{14}^{e} \\
k_{21}^{e} & k_{22}^{e} & k_{23}^{e} & k_{24}^{e} \\
k_{31}^{e} & k_{32}^{e} & k_{33}^{e} & k_{34}^{e} \\
k_{41}^{e} & k_{42}^{e} & k_{43}^{e} & k_{44}^{e}
\end{array}\right]\left\{\begin{array}{l}
V_{1}(t) \\
V_{2}(t) \\
V_{3}(t) \\
V_{4}(t)
\end{array}\right\}+\left[\begin{array}{llll}
M_{11}^{e} & M_{12}^{e} & M_{13}^{e} & M_{14}^{e} \\
M_{21}^{e} & M_{22}^{e} & M_{23}^{e} & M_{24}^{e} \\
M_{31}^{e} & M_{32}^{e} & M_{33}^{e} & M_{34}^{e} \\
M_{41}^{e} & M_{42}^{e} & M_{43}^{e} & M_{44}^{e}
\end{array}\right]\left\{\begin{array}{l}
V_{1}(t) \\
V_{2}(t) \\
V_{3}(t) \\
V_{4}(t)
\end{array}\right\}} \\
& {\left[\begin{array}{llll}
k_{11}^{e} & k_{12}^{e} & k_{13}^{e} & k_{14}^{e} \\
k_{21}^{e} & k_{22}^{e} & k_{23}^{e} & k_{24}^{e} \\
k_{31}^{e} & k_{32}^{e} & k_{33}^{e} & k_{34}^{e} \\
k_{41}^{e} & k_{42}^{e} & k_{43}^{e} & k_{44}^{e}
\end{array}\right]\left\{\begin{array}{l}
V_{1}(t) \\
V_{2}(t) \\
V_{3}(t) \\
V_{4}(t)
\end{array}\right\}+\left\{\begin{array}{l}
f_{1}^{e} \\
f_{2}^{e} \\
f_{3}^{e} \\
f_{4}^{e}
\end{array}\right\}+\left\{\begin{array}{l}
Q_{1}^{e} \\
Q_{2}^{e} \\
Q_{3}^{e} \\
Q_{4}^{e}
\end{array}\right\}=\left\{\begin{array}{l}
0 \\
0 \\
0 \\
0
\end{array}\right\},}
\end{aligned}
$$

or

$$
\left[k^{e}\right]\{V(t)\}+\left[M^{e}\right]\{V(t)\}+\left[C^{e}\right]\{V(t)\}+\left\{f^{e}\right\}+\left\{Q^{e}\right\}=0 .
$$

Equation (3.19) or (3.20) is the desired non-uniform finite element matrix equation for a typical element. In other words, the matrix equation is the governing equation describing the behavior of a typical finite element of the non-uniform beam traversed by a uniform partially distributed moving load. $\left[K^{e}\right]$ is the element stiffness matrix, $\left[M^{e}\right]$ is the element mass matrix, $\left[C^{e}\right]$ is the element centripetal matrix, $\left[f^{e}\right]$ is the element force vector and $\left[Q^{e}\right]$ is the element boundary term vector. 
For the sake of completeness, we state that the exact expressions for the various entries (sixteen of them) of the element stiffness matrix, for instance, can be obtained by substituting Eqs (2.2), (2.3), (2.5), (3.10) into Eqs (3.12), (3.16) and (3.17). These exact expressions are given in Appendix I. The exact expressions of the entries of the other element matrices and vectors can be similarly obtained.

The next step is assembling of the element equations. The procedure for assembling various corresponding matrices and vectors for several beam elements which constitute a mesh is well discussed in [a text]. For brevity, it suffices in this paper to state that for more than two elements, (say $\mathrm{z}$ elements), the assembled stiffness matrix, for instance, the corresponding assembled (overall) mass and centripetal matrices are of the same structure. The procedure also holds for the assembled load vectors. Hence the governing equation of motion describing the dynamic behaviour of the moving load problem with foundation is

$$
[K]\{V(t)\}+[C]\{\dot{V}(t)\}+[M]\{\ddot{V}(t)\}=\{F\}
$$

where $[K],[M],[C]$ and $[F]$ are the assembled (global or overall) stiffness, mass and centripetal matrices and load vector.

In order to obtain a complete and unique - solution of Eq.(3.21) the prescribed boundary conditions must be imposed on both the deflections/slopes and the shear force/bending moments, respectively.

Finally, for a harmonic free vibration system without the centripetal matrix, Eq.(3.21) reduces to

$$
\left([K]-\omega^{2}[M]\right)\{V(t)\}=0
$$

where $\omega^{2}$ denotes the natural frequency and $V(t)$ is the corresponding mode shape of the system. Various methods can be used to find the eigenvalue $\omega^{2}$ and the corresponding eigenvector $\{V(t)\}$ (Kwon and Bang, 196). The dynamic responses of the non-uniform beam under a uniform partially distributed moving load are obtained by solving the equation of motion Eq.(3.21) directly by the Newmark method (Abiala, 2008) and (Newmark, 1959).

\section{Numerical results for a moving load problem on a Winkler foundation and discussion}

In this section, a simply supported structural beam (see Fig.1a) resting on a Winkler foundation is, first, used to illustrate the procedure discussed hitherto. The total length of the beam is $L=10 \mathrm{~m}$, the mass density per beam's length $\rho=7.04 \mathrm{gm}^{3}$, the beam cross-sectional area $A=20 \mathrm{~m}^{2}$, the load's length $\in=0.5 \mathrm{~m}$ and the foundation elastic modulus $k=500$.

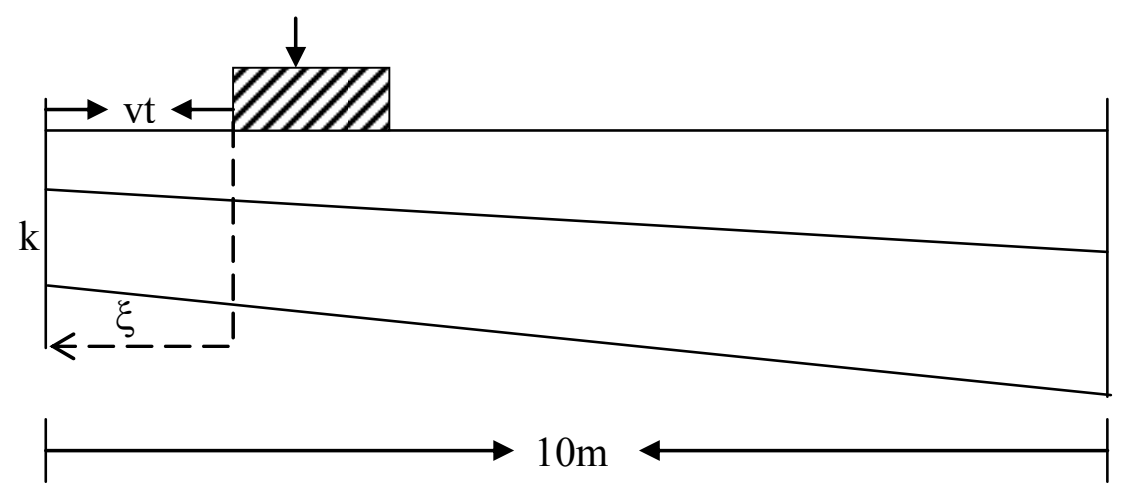

Fig.1a. A non-uniform beam on variable one- parameter foundation. 


\begin{tabular}{|c|c|c|c|c|c|}
\hline $1 \mathrm{~m}$ & $1.4 \mathrm{~m}$ & $1.5 \mathrm{~m}$ & $1.6 \mathrm{~m}$ & $2 \mathrm{~m}$ & $2.5 \mathrm{~m}$ \\
\hline $\mathrm{k}_{1}$ & $\mathrm{k}_{2}$ & $\mathrm{k}_{3}$ & $\mathrm{k}_{4}$ & $\mathrm{k}_{5}$ & $\mathrm{k}_{6}$ \\
\hline
\end{tabular}

Fig.1b. A discretized non- uniform beam on variable one-parameter foundation.

The beam is replaced by a discrete system composed of six non-uniform elements (Fig.1b) such that the length of each element is given as $L_{1}=1 \mathrm{~m}, L_{2}=1.4 \mathrm{~m}, L_{3}=1.5 \mathrm{~m}, L_{4}=1.6 \mathrm{~m}, L_{5}=2 \mathrm{~m}, L_{6}=2.5 \mathrm{~m}$, and the flexural rigidities are $E I_{1}=2.7728 \times 10^{5} \mathrm{Nm}, E I_{2}=3.9947 \times 10^{5} \mathrm{Nm}, E I_{3}=8.2858 \times 10^{5} \mathrm{Nm}, E I_{4}=2.6179 \times 10^{6} \mathrm{Nm}$, $E I_{5}=6.3936 \times 10^{6} \mathrm{Nm}, E I_{6}=9.393 \times 10^{6} \mathrm{Nm}$, while $A_{1}=2.0 \mathrm{~m}^{2}, A_{2}=2.8 \mathrm{~m}^{2}, A_{3}=3 \mathrm{~m}^{2}, A_{4}=3.2 \mathrm{~m}^{2}, A_{5}=4 \mathrm{~m}^{2}$ and $A_{6}=5 \mathrm{~m}^{2}$. In the analysis, the responses at various values of the foundation modulli are obtained, while effort is made to extend the study to a cantilever beam. The following observations were made:

(i) Effect of foundation: In order to study the effect of the foundation on the dynamic response of a nonuniform simply supported beam under a uniform partially distributed moving load and resting on a Winkler foundation, four values of the foundation parameter $k$ were used, viz $k=0,500,1400$, and 2000, respectively. It was observed from Fig.2 that the amplitude of the deflection increases with an increase in the foundation parameter $k$. In particular, it is found that the amplitude of the deflection of the system without foundation is lower than that involving the foundation.

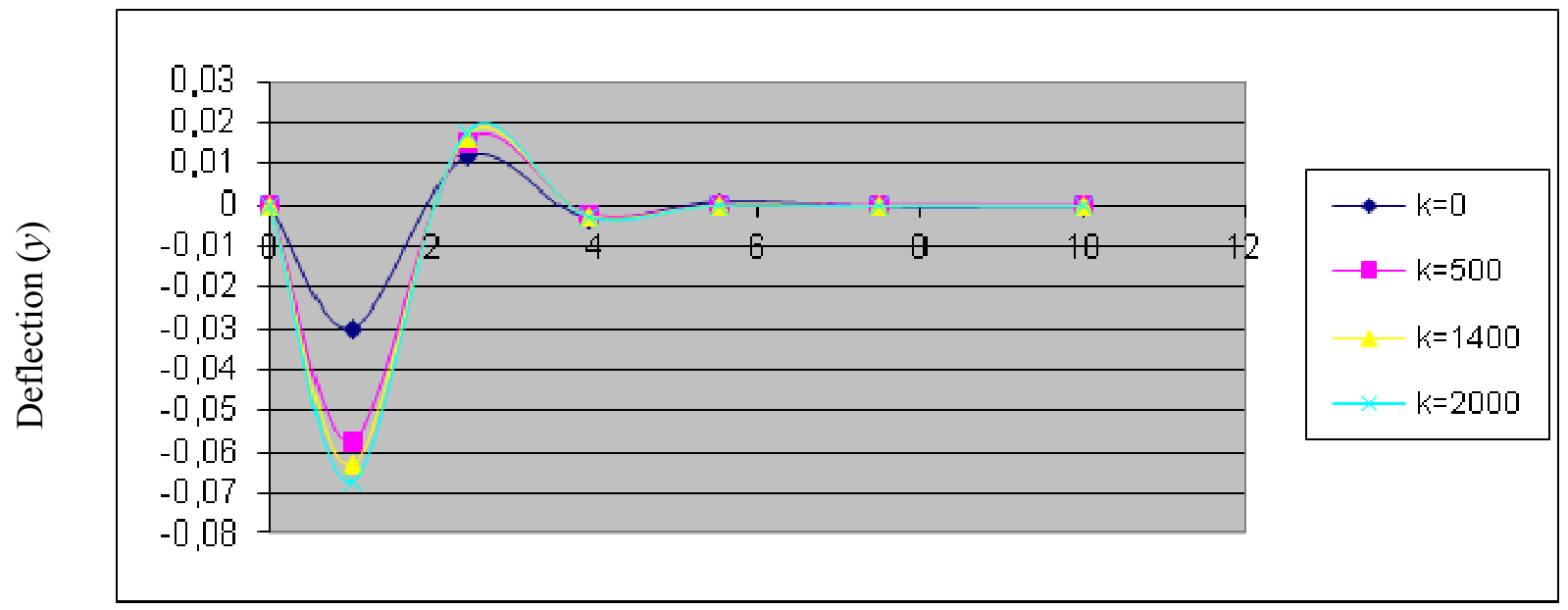

Distance $(x)$

Fig.2. Effects of increase in foundation on the dynamic response of a non-uniform simply supported bean with Winkler foundation under distributed moving loads.

(ii) Effect of velocity: To investigate the influence of the velocity of the load on the dynamic response of the non-uniform simply supported beam under uniform partially distributed moving load, the following various values of the velocity, viz $V_{0}=3 \mathrm{~m} / \mathrm{s}, 3.5 \mathrm{~m} / \mathrm{s}$ and $4 \mathrm{~m} / \mathrm{s}$ were used while $k=500$. It is observed that as the velocity increases, the amplitude of deflection also increases, (Fig.3), but after attaining the critical value of the velocity $V_{0}^{l}$, it is found that as the velocity increases, the amplitude of deflection decreases (see Fig.4). It is also noted that the critical value of the velocity is smaller than that when there was no foundation. This critical value of the velocity is found to be $4.5 \mathrm{~m} / \mathrm{s}$. 


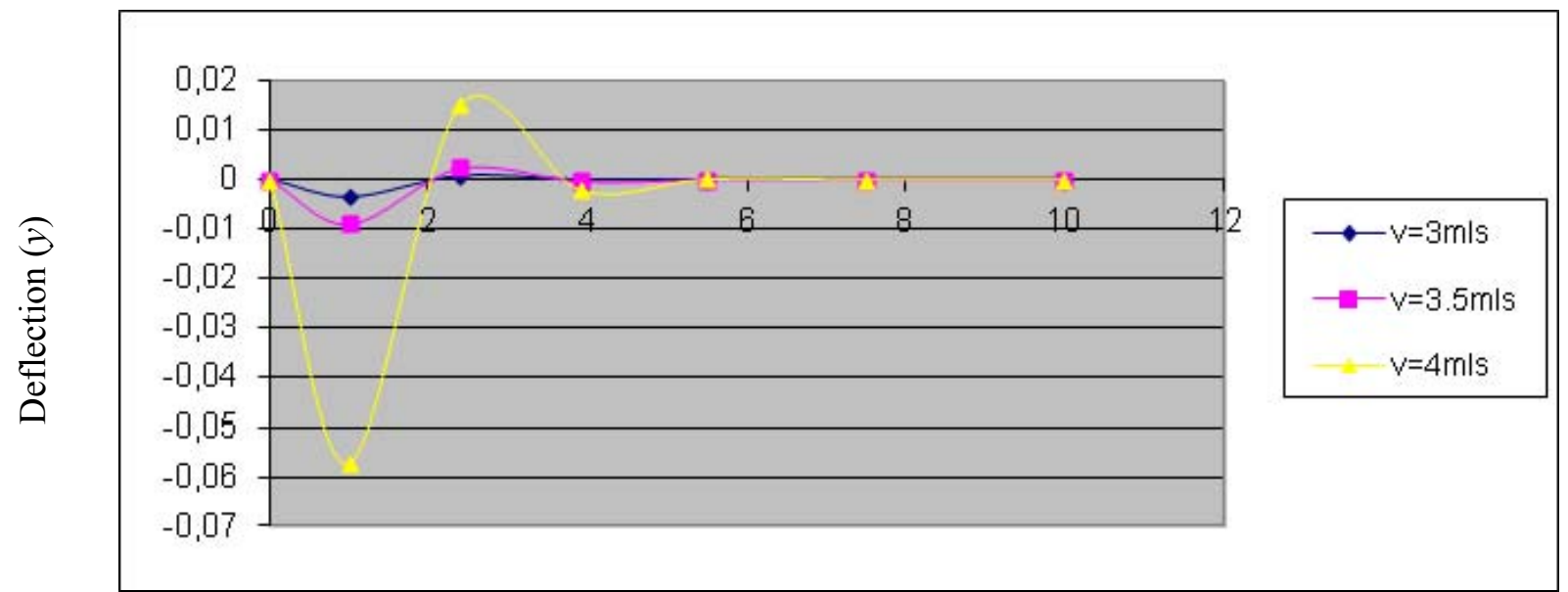

Distance $(x)$

Fig.3. Effects of increase in velocity on the dynamic response of a non-uniform simply supported bean with Winkler foundation under distributed moving loads.



Distance $(x)$

Fig.4. Effects of exceeding the critical value of the velocity on the dynamic response of a non-uniform simply supported bean with Winkler foundation under distributed moving loads.

(iii) Effect of the length of the load: Next, the effect of the length of the load $(\varepsilon)$ on the dynamic response of a simply supported non-uniform beam supported by an elastic foundation is investigated. For this purpose, the following values of the load's length $\varepsilon=0.5,0.7$ and 0.9 were considered. It is observed that as the load's length increases, the amplitude of the deflection decreases (see Fig.5). This is in contradiction with the situation involving no foundation. 


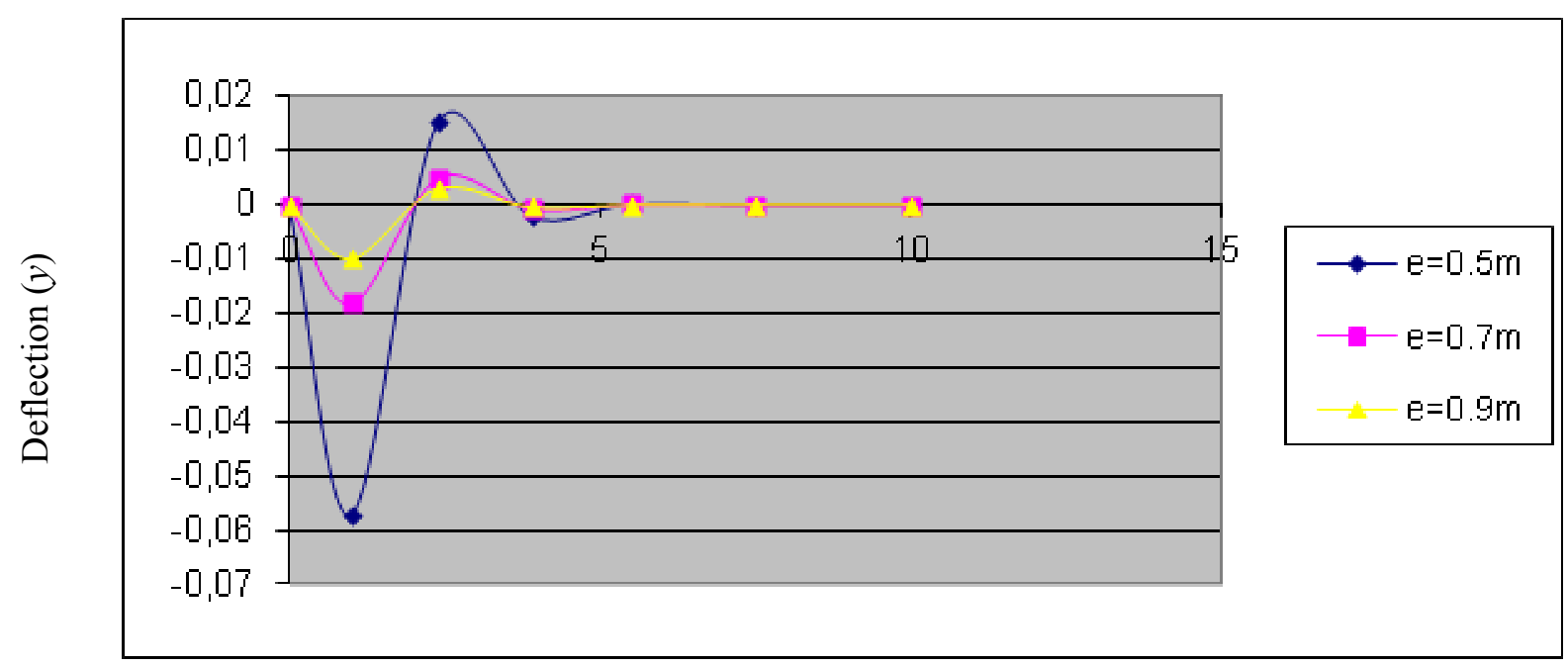

Distance $(x)$

Fig.5. Effects of increase in load's length on the dynamic response of a non-uniform simply supported bean with Winkler foundation under distributed moving loads.

(iv) Effect of length of the beam element: The following three different span-lengths of the beam, $L=$ $10 \mathrm{~m}, 16 \mathrm{~m}$ and $22 \mathrm{~m}$ were considered for the purpose of studying the influences of the beam's length on the dynamic response of simply supported non-uniform beam resting on a variable Winkler foundation. It can be seen from Fig. 6 that as the span-length of the beam increases, the amplitude of the deflection decreases. This is contrary to the case when the beam is not resting on an elastic foundation.

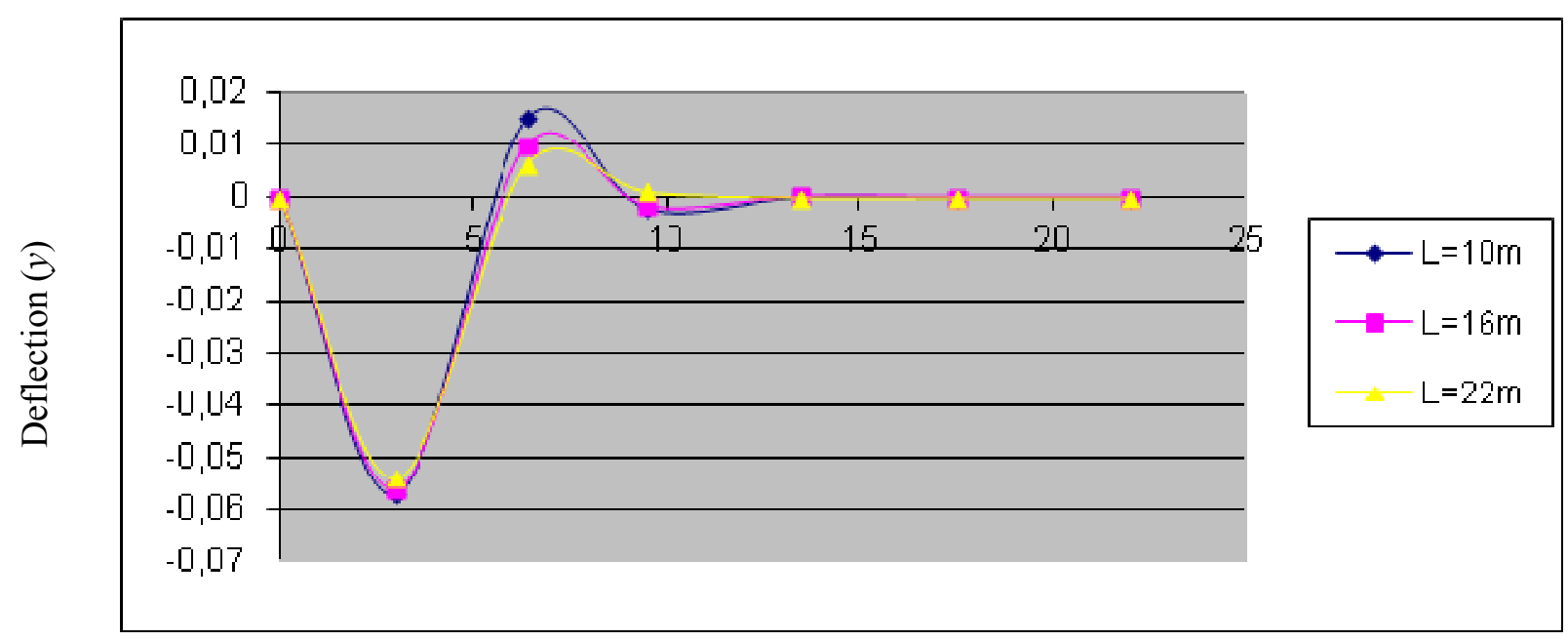

Distance $(x)$

Fig.6. Effects of increase in the length of the beam on the dynamic response of a non-uniform simply supported bean with Winkler foundation under distributed moving loads.

(v) Effect of changes in boundary conditions: If the associated boundary conditions are changed from being simply supported to that of being fixed-free, it is found that the behavioural pattern of the responses is in the opposite direction. In particular, it is found that unlike the simply supported conditions, the response amplitude of the non uniform beam decreases as the velocity increases (see 
Fig.7), for $V o>V o$ (see Fig.8). In fact, the critical value of the velocity in this case is about $6 \mathrm{~m} / \mathrm{s}$, which is higher than that when the beam is simply supported. Furthermore, for a cantilever beam, the response amplitude decreases with an increase in the foundation parameter K(see Fig.9), which contradicts the prevailing situation for a simply supported beam. However, just like the simply supported beam, the response amplitude decreases as the load's length increases(see Fig.10), while the responses if the beam's length is increased behave in the same manner as when the beam is simply supported (see Fig.11).



Distance $(x)$

Fig.7. Effects of increase in velocity on the dynamic response of cantilever beam with Winkler foundation under distributed moving loads.

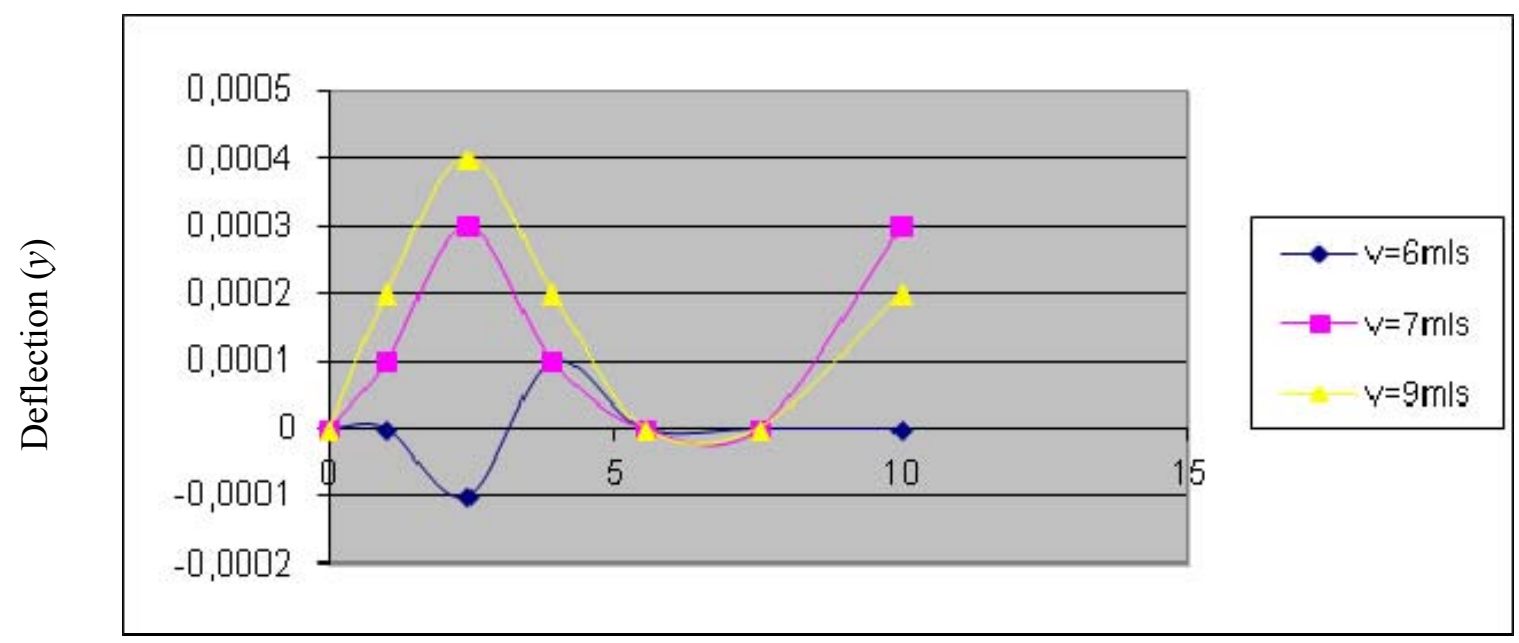

Distance $(x)$

Fig.8. Effects of exceeding the critical value of velocity on the dynamic response of cantilever beam with Winkler foundation under distributed moving loads. 


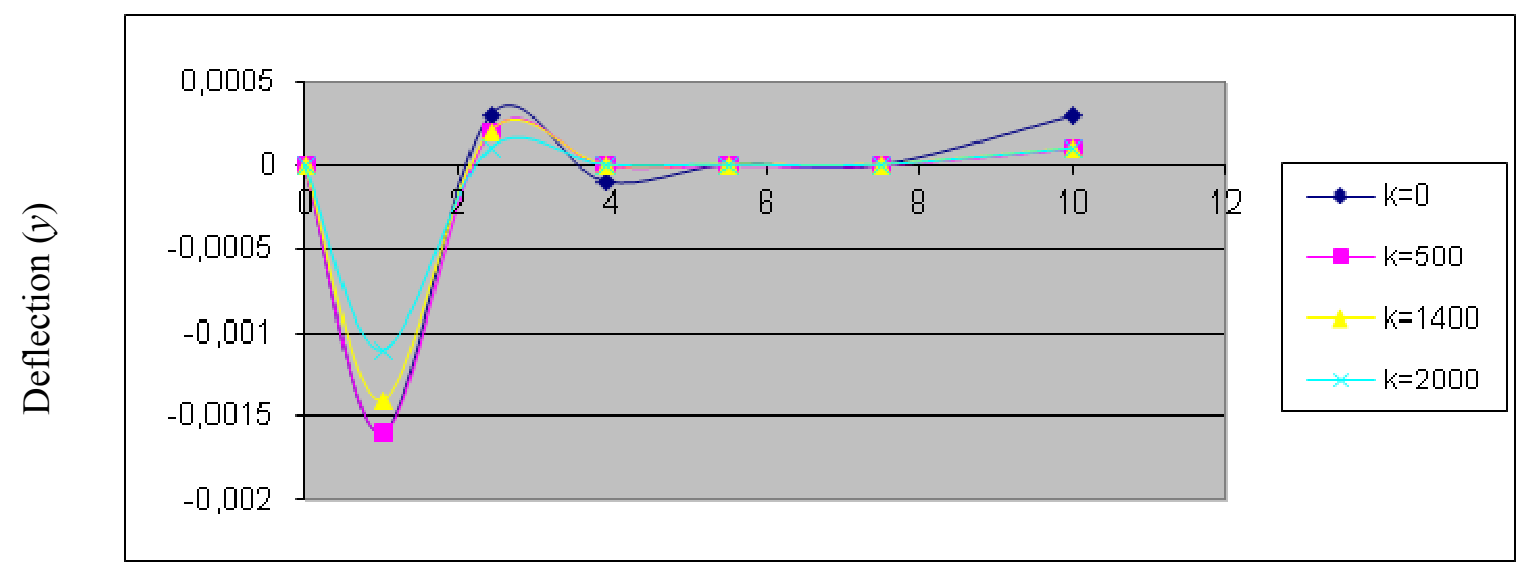

Distance $(x)$

Fig.9. Effects of increase in foundation on the dynamic response of cantilever beam with Winkler foundation under distributed moving loads.

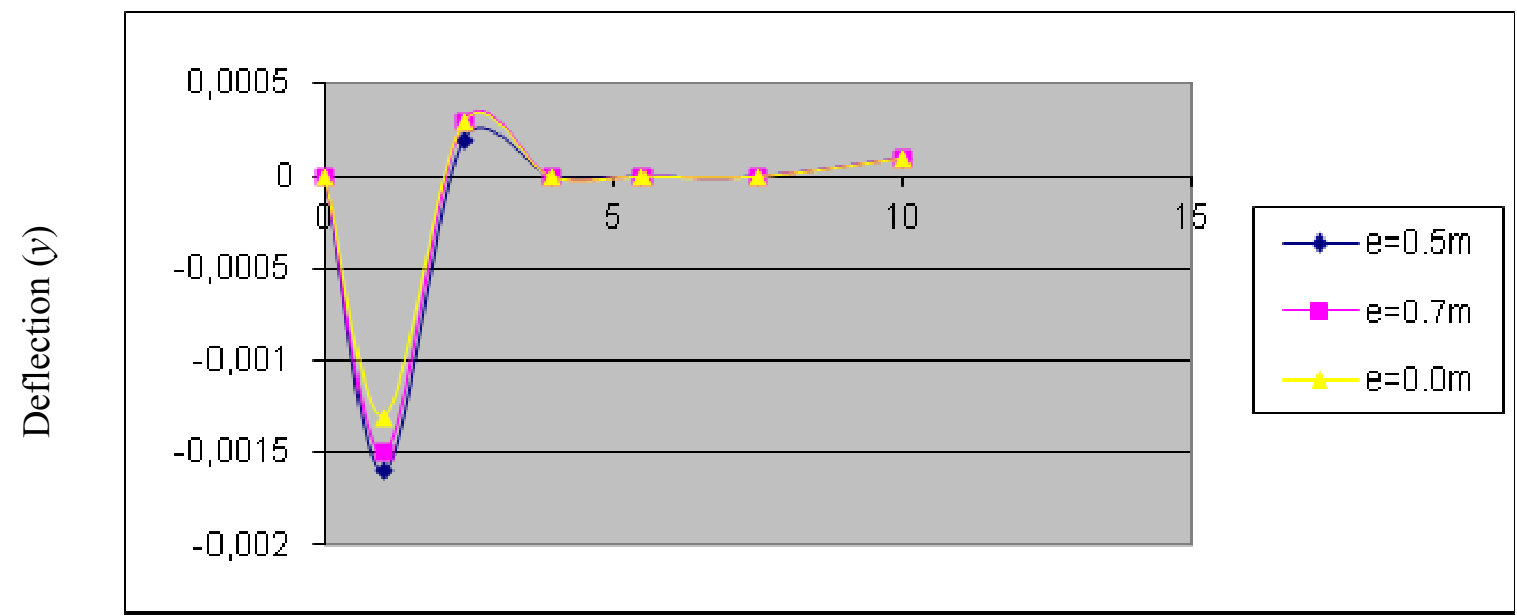

Distance $(x)$

Fig.10. Effects of increase in load's length on the dynamic response of cantilever beam with Winkler foundation under distributed moving loads.

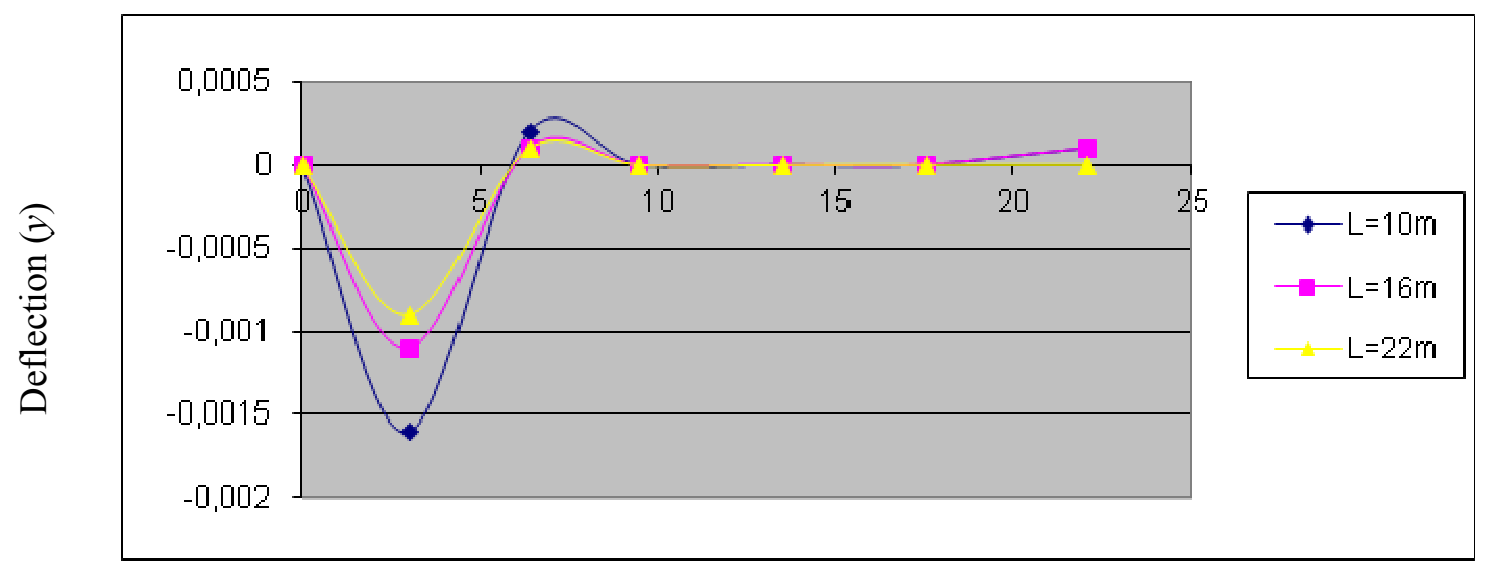

Distance $(x)$

Fig.11. Effects of increase in span-length of the beam on the dynamic response of cantilever beam with Winkler foundation under distributed moving loads. 


\section{Conclusions}

Vibration analysis of a non-uniform beam subjected to a uniform partially distributed moving load and resting on a variable Winkler foundation using the finite element method has been developed in this paper. The overall finite element equations were solved employing Newmark's numerical integration technique with the aid of Computer codes written in Visual Basic. The influence of the speed of the moving load, the boundary conditions of the beam, the span length of the beam, the load's length and the elastic modulus of the foundation are obtained. Both simply supported and cantilever non-uniform beams are considered.

On the basis of the configurations of vibration chosen, one may draw the following conclusions:

a) The maximum amplitude of the deflection of a simply supported non-uniform beam resting on a nonuniform Winkler foundation and traversed by a uniform partially distributed moving load, increases as the foundation parameter increases.

b) An increase in the span length of a non-uniform, simply supported or cantilever beam continuously supported by a non-uniform Winkler foundation under a uniform partially distributed moving load, yields a decrease in the maximum amplitude of the deflection of the beam.

c) For a non-uniform cantilever beam resting on a non-uniform Winkler foundation under a uniform partially distributed moving load, and for speeds of the moving load which are less than the critical speed, the maximum amplitude decreases as the speed increases and reverses for speeds greater than the critical speed.

\section{APPENDIX 1}

$$
\left[\begin{array}{cccccccc}
k_{11}^{e 1} & k_{12}^{e 1} & k_{13}^{e 1} & k_{14}^{e 1} & 0 & 0 & 0 & 0 \\
k_{21}^{e 1} & k_{22}^{e 1} & k_{23}^{e 1} & k_{24}^{e 1} & 0 & 0 & 0 & 0 \\
k_{31}^{e 1} & k_{32}^{e 1} & k_{33}^{e 1}+k_{11}^{e 2} & k_{34}^{e 1}+k_{12}^{e 2} & k_{13}^{e 2} & k_{14}^{e 2} & 0 & 0 \\
k_{41}^{e 1} & k_{42}^{e 1} & k_{43}^{e 1}+k_{21}^{e 2} & k_{44}^{e 1}+k_{22}^{e 2} & k_{23}^{e 2} & k_{24}^{e 2} & 0 & 0 \\
0 & 0 & k_{31}^{e 2} & k_{32}^{e 2} & k_{33}^{e 2}+k_{11}^{e 3} & k_{34}^{e 2}+k_{12}^{e 3} & k_{13}^{e 3} & k_{14}^{e 3} \\
0 & 0 & k_{41}^{e 2} & k_{42}^{e 2} & k_{43}^{e 2}+k_{21}^{e 3} & k_{44}^{e 2}+k_{22}^{e 3} & k_{23}^{e 3} & k_{14}^{e 3} \\
0 & 0 & 0 & 0 & k_{31}^{e 3} & k_{32}^{e 3} & k_{33}^{e 3} & k_{34}^{e 3} \\
0 & 0 & 0 & 0 & k_{41}^{e 3} & k_{43}^{e 3} & k_{43}^{e 3} & k_{44}^{e 3} \\
- & - & - & - & - & - & - & - \\
0 & 0 & k_{31}^{z-1} & k_{32}^{z-1} & k_{33}^{z-1}+k_{11}^{z} & k_{34}^{z-1}+k_{12}^{z} & k_{13}^{z} & k_{14}^{z} \\
0 & 0 & k_{41}^{z-1} & k_{42}^{z-1} & k_{43}^{z-1}+k_{21}^{z} & k_{44}^{z-1}+k_{22}^{z} & k_{23}^{z} & k_{24}^{z} \\
0 & 0 & 0 & 0 & k_{31}^{z} & k_{32}^{z} & k_{33}^{z} & k_{34}^{z} \\
0 & 0 & 0 & 0 & k_{41}^{z} & k_{42}^{z} & k_{43}^{z} & k_{44}^{z}
\end{array}\right]
$$

Such that for a single element

$$
\begin{aligned}
& K_{11}^{e}=\int_{\sum_{e=1}^{e=1} L_{e}}^{\sum_{e=1}^{r} L_{e}}\left\{\sum_{r=1}^{n s p a n} E I_{r}\left(x-\sum_{e=1}^{r-1} L_{e}\right)\right\}\left[\frac{36}{l^{4}}-\frac{144 x}{l^{5}}+\frac{144 x^{2}}{l^{6}}\right] d x+ \\
& +\frac{p v^{2}}{\varepsilon}\left[\left(-\frac{6 \eta}{l^{2}}+\frac{6 \eta^{3}}{l^{4}}-\frac{12 \eta^{4}}{l^{5}}+\frac{6 \eta^{2}}{l^{3}}+\frac{24 \eta^{5}}{5 l^{6}}\right)-\left(-\frac{6 \mu}{l^{2}}+\frac{6 \mu^{3}}{l^{4}}-\frac{12 \mu^{4}}{l^{5}}+\frac{6 \mu^{2}}{l^{3}}+\frac{24 \mu^{5}}{5 l^{6}}\right)\right]+ \\
& +k \int_{0}^{l}\left[\left(4 x-3 x^{2}+x^{3}\right)\left(1-\frac{6 x^{2}}{l^{2}}+\frac{4 x^{3}}{l^{3}}+\frac{9 x^{4}}{l^{4}}-\frac{12 x^{5}}{l^{5}}+\frac{4 x^{6}}{l^{6}}\right)\right] d x,
\end{aligned}
$$




$$
\begin{aligned}
& K_{12}^{e}=\int_{\sum_{e=1}^{e=1}}^{\sum_{r-1}^{r} L_{e}}\left\{\left\{\sum_{r=1}^{n s p a n} E I_{r}\left(x-\sum_{e=1}^{r-1} L_{e}\right)\right\}\left[\frac{24}{l^{3}}-\frac{84 x}{l^{4}}+\frac{72 x^{2}}{l^{5}}\right] d x+\right. \\
& +\frac{p v^{2}}{\varepsilon}\left[\left(-\frac{3 \eta^{2}}{l^{2}}+\frac{8 \eta^{3}}{l^{3}}-\frac{15 \eta^{4}}{l^{4}}+\frac{12 \eta^{5}}{5 l^{5}}\right)-\left(-\frac{3 \mu^{2}}{l^{2}}+\frac{8 \mu^{3}}{l^{3}}-\frac{15 \mu^{4}}{l^{4}}+\frac{12 \mu^{5}}{5 l^{5}}\right)\right]+ \\
& -k \int_{0}^{l}\left[\left(4 x-3 x^{2}+x^{3}\right)\left(x-\frac{2 x^{2}}{l}-\frac{2 x^{3}}{l^{2}}+\frac{8 x^{4}}{l^{2}}-\frac{7 x^{5}}{l^{4}}+\frac{3 x^{6}}{l^{5}}\right)\right] d x, \\
& K_{13}^{e}=\int_{\sum_{e=1}^{e=1}}^{\sum_{r-1}^{r} L_{e}}\left\{\sum_{r=1}^{n s p a n} E I_{r}\left(x-\sum_{e=1}^{r-1} L_{e}\right)\right\}\left[-\frac{36}{l^{4}}+\frac{144 x}{l^{5}}-\frac{144 x^{2}}{l^{6}}\right] d x+ \\
& +\frac{p v^{2}}{\varepsilon}\left[\left(-\frac{6 \eta^{3}}{l^{4}}+\frac{12 \eta^{4}}{l^{5}}-\frac{24 \eta^{5}}{5 l^{6}}\right)-\left(-\frac{6 \mu^{3}}{l^{4}}+\frac{12 \mu^{4}}{l^{5}}-\frac{24 \mu^{5}}{5 l^{6}}\right)\right]+ \\
& +k \int_{0}^{l}\left[\left(4 x-3 x^{2}+x^{3}\right)\left(\frac{3 x^{2}}{l^{2}}+\frac{2 x^{3}}{l^{3}}-\frac{9 x^{4}}{l^{4}}+\frac{12 x^{5}}{l^{5}}-\frac{4 x^{6}}{l^{6}}\right)\right] d x, \\
& K_{14}^{e}=\int_{\sum_{e=1}^{e-1} L_{e}}^{\sum_{r=1}^{r} L_{e}}\left\{\sum_{r=1}^{n s p a n} E I_{r}\left(x-\sum_{e=1}^{r-1} L_{e}\right)\right\}\left[\frac{12}{l^{3}}-\frac{6 x}{l^{4}}+\frac{72 x^{2}}{l^{5}}\right] d x+ \\
& +\frac{p v^{2}}{\varepsilon}\left[\left(\frac{2 \eta^{3}}{l^{3}}-\frac{9 \eta^{4}}{2 l^{4}}+\frac{12 \eta^{5}}{5 l^{5}}\right)-\left(\frac{2 \mu^{3}}{l^{3}}-\frac{9 \mu^{4}}{2 l^{4}}+\frac{12 \mu^{5}}{5 l^{5}}\right)\right]+ \\
& -k \int_{0}^{l}\left[\left(4 x-3 x^{2}+x^{3}\right)\left(-\frac{x^{3}}{l}+\frac{x^{3}}{l^{2}}+\frac{3 x^{4}}{l^{2}}-\frac{5 x^{5}}{l^{5}}+\frac{2 x^{6}}{l^{3}}\right)\right] d x, \\
& K_{21}^{e}=\int_{\sum_{e=1}^{e=1}}^{\sum_{r-1}^{r} L_{e}}\left\{\sum_{r=1}^{n s p a n} E I_{r}\left(x-\sum_{e=1}^{r-1} L_{e}\right)\right\}\left[\frac{24}{l^{3}}-\frac{84 x}{l^{4}}+\frac{72 x^{2}}{l^{5}}\right] d x+ \\
& +\frac{p v^{2}}{\varepsilon}\left[\left(-\frac{4 \eta}{l}+\frac{4 \eta^{3}}{l^{3}}-\frac{13 \eta^{4}}{2 l^{4}}+\frac{3 \eta^{2}}{l^{2}}+\frac{12 \eta^{5}}{5 l^{5}}\right)-\left(-\frac{4 \mu}{l}+\frac{4 \mu^{3}}{l^{3}}-\frac{13 \mu^{4}}{2 l^{4}}+\frac{3 \mu^{2}}{l^{2}}+\frac{12 \mu^{5}}{5 l^{5}}\right)\right]+ \\
& +k \int_{0}^{l}\left[\left(4 x-3 x^{2}+x^{3}\right)\left(x-\frac{2 x^{2}}{l}-\frac{2 x^{3}}{l^{2}}+\frac{8 x^{4}}{l^{2}}-\frac{7 x^{5}}{l^{4}}+\frac{3 x^{6}}{l^{5}}\right)\right] d x
\end{aligned}
$$




$$
\begin{aligned}
& K_{22}^{e}=\int_{\sum_{e=1}^{e=1} L_{e}}^{\sum_{r=1}^{r} L_{e}}\left\{\sum_{r=1}^{n s p a n} E I_{r}\left(x-\sum_{e=1}^{r-1} L_{e}\right)\right\}\left[\frac{16}{l^{2}}-\frac{48 x}{l^{3}}+\frac{36 x^{2}}{l^{4}}\right] d x+ \\
& +\frac{p v^{2}}{\varepsilon}\left[\left(-\frac{2 \eta^{2}}{l}+\frac{14 \eta^{3}}{3 l^{2}}-\frac{4 \eta^{4}}{l^{3}}+\frac{6 \eta^{5}}{5 l^{4}}\right)-\left(-\frac{2 \mu^{2}}{l}+\frac{14 \mu^{3}}{3 l^{2}}-\frac{4 \mu^{4}}{l^{3}}+\frac{6 \mu^{5}}{5 l^{4}}\right)\right]+ \\
& +k \int_{0}^{l}\left[\left(4 x-3 x^{2}+x^{3}\right)\left(x^{2}-\frac{4 x^{3}}{l}+\frac{6 x^{4}}{l^{2}}-\frac{4 x^{5}}{l^{3}}+\frac{x^{6}}{l^{4}}\right)\right] d x,
\end{aligned}
$$

$$
\begin{aligned}
& K_{23}^{e}=\int_{\sum_{e=1}^{e=1} L_{e}}^{\sum_{r-l}^{r} L_{e}}\left\{\sum_{r=1}^{n s p a n} E I_{r}\left(x-\sum_{e=1}^{r-1} L_{e}\right)\right\}\left[-\frac{24}{l^{3}}+\frac{84 x}{l^{4}}-\frac{72 x^{2}}{l^{5}}\right] d x+ \\
& +\frac{p v^{2}}{\varepsilon}\left[\left(-\frac{4 \eta^{3}}{l^{3}}+\frac{13 \eta^{4}}{2 l^{4}}-\frac{12 \eta^{5}}{5 l^{5}}\right)-\left(-\frac{4 \mu^{3}}{l^{3}}+\frac{13 \mu^{4}}{2 l^{4}}-\frac{12 \mu^{5}}{5 l^{5}}\right)\right]+ \\
& +k \int_{0}^{l}\left[\left(4 x-3 x^{2}+x^{3}\right)\left(\frac{3 x^{3}}{l^{2}}-\frac{8 x^{4}}{l^{3}}+\frac{7 x^{5}}{l^{4}}-\frac{2 x^{6}}{l^{5}}\right)\right] d x,
\end{aligned}
$$$$
K_{24}^{e}=\int_{\sum_{e=1}^{e-1} L_{e}}^{\sum_{r=1}^{r} L_{e}}\left\{\sum_{r=1}^{n s p a n} E I_{r}\left(x-\sum_{e=1}^{r-1} L_{e}\right)\right\}\left[\frac{8}{l^{2}}-\frac{36 x}{l^{3}}+\frac{36 x^{2}}{l^{4}}\right] d x+
$$$$
+\frac{p v^{2}}{\varepsilon}\left[\left(\frac{4 \eta^{3}}{3 l^{2}}-\frac{5 \eta^{4}}{2 l^{3}}+\frac{6 \eta^{5}}{5 l^{4}}\right)-\left(\frac{4 \mu^{3}}{3 l^{2}}-\frac{5 \mu^{4}}{2 l^{3}}+\frac{6 \mu^{5}}{5 l^{4}}\right)\right]+
$$$$
-k \int_{0}^{l}\left[\left(4 x-3 x^{2}+x^{3}\right)\left(-\frac{x^{3}}{l}+\frac{3 x^{4}}{l^{2}}-\frac{3 x^{5}}{l^{3}}+\frac{x^{6}}{l^{4}}\right)\right] d x,
$$

$$
\begin{aligned}
& K_{31}^{e}=\int_{\sum_{e=1}^{e=1} L_{e}}^{\sum_{r=1}^{r} L_{e}}\left\{\sum_{r=1}^{n s p a n} E I_{r}\left(x-\sum_{e=1}^{r-1} L_{e}\right)\right\}\left[-\frac{36}{l^{4}}+\frac{144 x}{l^{5}}-\frac{144 x^{2}}{l^{6}}\right] d x+ \\
& +\frac{p v^{2}}{\varepsilon}\left[\left(\frac{6 \eta}{l^{2}}-\frac{6 \eta^{3}}{l^{4}}+\frac{12 \eta^{4}}{l^{5}}-\frac{6 \eta^{2}}{l^{3}}-\frac{24 \eta^{5}}{5 l^{6}}\right)-\left(\frac{6 \mu}{l^{2}}-\frac{6 \mu^{3}}{l^{4}}+\frac{12 \mu^{4}}{l^{5}}-\frac{6 \eta^{2}}{l^{3}}-\frac{24 \mu^{5}}{5 l^{6}}\right)\right]+ \\
& +k \int_{0}^{l}\left[\left(4 x-3 x^{2}+x^{3}\right)\left(\frac{3 x^{2}}{l^{2}}+\frac{2 x^{3}}{l^{3}}-\frac{9 x^{4}}{l^{4}}+\frac{12 x^{5}}{l^{5}}-\frac{4 x^{6}}{l^{6}}\right)\right] d x,
\end{aligned}
$$




$$
\begin{aligned}
& K_{32}^{e}=\int_{\sum_{e=1}^{e=1} L_{e}}^{\sum_{r=1}^{r} L_{e}}\left\{\sum_{r=1}^{n s p a n} E I_{r}\left(x-\sum_{e=1}^{r-1} L_{e}\right)\right\}\left[-\frac{24}{l^{3}}+\frac{84 x}{l^{4}}-\frac{72 x^{2}}{l^{5}}\right] d x+ \\
& +\frac{p v^{2}}{\varepsilon}\left[\left(\frac{3 \eta^{2}}{l^{2}}-\frac{8 \eta^{3}}{l^{3}}+\frac{15 \eta^{4}}{2 l^{4}}-\frac{12 \eta^{5}}{5 l^{5}}\right)-\left(\frac{3 \mu^{2}}{l^{2}}-\frac{8 \mu^{3}}{l^{3}}+\frac{15 \mu^{4}}{2 l^{4}}-\frac{12 \mu^{5}}{5 l^{5}}\right)\right]+ \\
& +k \int_{0}^{l}\left[\left(4 x-3 x^{2}+x^{3}\right)\left(\frac{3 x^{3}}{l^{2}}-\frac{8 x^{4}}{l^{3}}+\frac{7 x^{5}}{l^{4}}-\frac{2 x^{6}}{l^{5}}\right)\right] d x, \\
& K_{33}^{e}=\int_{\sum_{e=1}^{e-1} L_{e}}^{\sum_{r=1}^{r} L_{e}}\left\{\sum_{r=1}^{n s p a n} E I_{r}\left(x-\sum_{e=1}^{r-1} L_{e}\right)\right\}\left[\frac{36}{l^{4}}-\frac{144 x}{l^{5}}+\frac{144 x^{2}}{l^{6}}\right] d x+ \\
& +\frac{p v^{2}}{\varepsilon}\left[\left(\frac{6 \eta^{3}}{l^{4}}-\frac{12 \eta^{4}}{l^{5}}+\frac{24 \eta^{5}}{5 l^{6}}\right)-\left(\frac{6 \mu^{3}}{l^{4}}-\frac{12 \mu^{4}}{l^{5}}+\frac{24 \mu^{5}}{5 l^{6}}\right)\right]+ \\
& +k \int_{0}^{l}\left[\left(4 x-3 x^{2}+x^{3}\right)\left(\frac{9 x^{4}}{l^{4}}-\frac{12 x^{5}}{l^{5}}+\frac{4 x^{4}}{l^{5}}\right)\right] d x, \\
& K_{34}^{e}=\int_{\sum_{e=1}^{e=1}}^{\sum_{r=1}^{r} L_{e}}\left\{\sum_{r=1}^{n s p a n} E I_{r}\left(x-\sum_{e=1}^{r-1} L_{e}\right)\right\}\left[-\frac{12}{l^{3}}+\frac{60 x}{l^{4}}-\frac{72 x^{2}}{l^{5}}\right] d x+ \\
& +\frac{p v^{2}}{\varepsilon}\left[\left(-\frac{2 \eta^{3}}{l^{3}}+\frac{9 \eta^{4}}{2 l^{4}}-\frac{12 \eta^{5}}{5 l^{5}}\right)-\left(-\frac{2 \mu^{3}}{l^{3}}+\frac{9 \mu^{4}}{2 l^{4}}-\frac{12 \mu^{5}}{5 l^{5}}\right)\right]+ \\
& -k \int_{0}^{l}\left[\left(4 x-3 x^{2}+x^{3}\right)\left(-\frac{3 x^{4}}{l^{3}}+\frac{5 x^{5}}{l^{4}}-\frac{2 x^{6}}{l^{5}}\right)\right] d x, \\
& K_{41}^{e}=\int_{\sum_{e=1}^{e=1} L_{e}}^{\sum_{r=1}^{r} L_{e}}\left\{\sum_{r=1}^{n s p a n} E I_{r}\left(x-\sum_{e=1}^{r-1} L_{e}\right)\right\}\left[\frac{12}{l^{3}}-\frac{60 x}{l^{4}}+\frac{72 x^{2}}{l^{5}}\right] d x+ \\
& \left.+\frac{p v^{2}}{\varepsilon}\left[\left(-\frac{2 \eta}{l}+\frac{2 \eta^{3}}{l^{3}}-\frac{11 \eta^{4}}{2 l^{4}}+\frac{3 \eta^{2}}{l^{2}}+\frac{12 \eta^{5}}{5 l^{5}}\right)\right)-\left(-\frac{2 \mu}{l}+\frac{2 \mu^{3}}{l^{3}}-\frac{11 \mu^{4}}{2 l^{4}}+\frac{3 \mu^{2}}{l^{2}}+\frac{12 \mu^{5}}{5 l^{5}}\right)\right]+ \\
& -k \int_{0}^{l}\left[\left(4 x-3 x^{2}+x^{3}\right)\left(-\frac{x^{3}}{l}+\frac{x^{3}}{l^{2}}+\frac{3 x^{4}}{l^{2}}-\frac{5 x^{5}}{l^{5}}+\frac{2 x^{6}}{l^{3}}\right)\right] d x,
\end{aligned}
$$




$$
\begin{aligned}
& K_{42}^{e}=\int_{\sum_{e=1}^{e=1}}^{\sum_{r-1}^{r} L_{e}}\left\{\left\{\sum_{r=1}^{n s p a n} E I_{r}\left(x-\sum_{e=1}^{r-1} L_{e}\right)\right\}\left[\frac{8}{l^{2}}-\frac{36 x}{l^{3}}+\frac{36 x^{2}}{l^{4}}\right] d x+\right. \\
& +\frac{p v^{2}}{\varepsilon}\left[\left(-\frac{\eta^{2}}{l}+\frac{10 \eta^{3}}{3 l^{2}}-\frac{7 \eta^{4}}{2 l^{3}}+\frac{6 \eta^{5}}{5 l^{4}}\right)-\left(-\frac{\mu^{2}}{l}+\frac{10 \mu^{3}}{3 l^{2}}-\frac{7 \mu^{4}}{2 l^{3}}+\frac{6 \mu^{5}}{5 l^{4}}\right)\right]+ \\
& -k \int_{0}^{l}\left[\left(4 x-3 x^{2}+x^{3}\right)\left(-\frac{x^{3}}{l}+\frac{3 x^{4}}{l^{2}}-\frac{3 x^{5}}{l^{3}}+\frac{x^{6}}{l^{4}}\right)\right] d x, \\
& K_{43}^{e}=\int_{\sum_{e=1}^{e=1}}^{\sum_{r=1}^{r} L_{e}}\left\{\sum_{r=1}^{n s p a n} E I_{r}\left(x-\sum_{e=1}^{r-1} L_{e}\right)\right\}\left[-\frac{12}{l^{3}}+\frac{60 x}{l^{4}}-\frac{72 x^{2}}{l^{5}}\right] d x+ \\
& +\frac{p v^{2}}{\varepsilon}\left[\left(-\frac{2 \eta^{3}}{l^{3}}+\frac{11 \eta^{4}}{2 l^{4}}-\frac{12 \eta^{5}}{5 l^{5}}\right)-\left(-\frac{2 \mu^{3}}{l^{3}}+\frac{11 \mu^{4}}{2 l^{4}}+\frac{12 \mu^{5}}{5 l^{5}}\right)\right]+ \\
& -k \int_{0}^{l}\left[\left(4 x-3 x^{2}+x^{3}\right)\left(-\frac{3 x^{4}}{l^{3}}+\frac{5 x^{5}}{l^{4}}-\frac{2 x^{6}}{l^{5}}\right)\right] d x, \\
& K_{44}^{e}=\int_{\sum_{e=1}^{e=1} L_{e}}^{\sum_{r-1}^{r} L_{e}}\left\{\sum_{r=1}^{n s p a n} E I_{r}\left(x-\sum_{e=1}^{r-1} L_{e}\right)\right\}\left[\frac{4}{l^{2}}-\frac{24 x}{l^{3}}+\frac{36 x^{2}}{l^{4}}\right] d x+ \\
& +\frac{p v^{2}}{\varepsilon}\left[\left(\frac{2 \eta^{3}}{3 l^{2}}-\frac{2 \eta^{4}}{l^{3}}+\frac{6 \eta^{5}}{5 l^{4}}\right)-\left(\frac{2 \mu^{3}}{3 l^{2}}-\frac{2 \mu^{4}}{l^{3}}+\frac{6 \mu^{5}}{5 l^{4}}\right)\right]+ \\
& +k \int_{0}^{l}\left[\left(4 x-3 x^{2}+x^{3}\right)\left(\frac{x^{4}}{l^{2}}-\frac{2 x^{5}}{l^{3}}+\frac{x^{6}}{l^{4}}\right)\right] d x \text {. }
\end{aligned}
$$

\section{Nomenclature}

$$
\begin{aligned}
A(x) & - \text { cross section area of the beam } \\
E I & - \text { flexural rigidity of the beam } \\
F R(x, t) & - \text { foundation reaction (pressure) } \\
G(x) & - \text { weight function } \\
g & - \text { acceleration due to gravity } \\
H(x) & - \text { Heavyside function } \\
H_{K}(x) & - \text { Hermite cubic shape functions } \\
K & - \text { foundation modulus parameter } \\
k & - \text { an arbitrary constant } \\
l^{e} & - \text { typical length of the beam element } \\
m_{f} & - \text { mass of the foundation } \\
m_{L} & - \text { mass of the moving load } \\
Q(x, t) & - \text { externally applied moving load }
\end{aligned}
$$






\section{References}

Abiala I.O. (2008): Vibration analysis of non-uniform beams under uniformly distributed moving loads using finite element method. - Ph.D Thesis, University of Ilorin, Ilorin.

Ahmadian M., Esmailzadeh E. and Asgari M. (2006): Dynamic analysis of non-uniform cross sections beam under moving mass using finite element method. - Proceedings of the 4th CSME Forum, Calgari, Alberta, Canada, May $21^{\text {st }}-23^{\text {rd }}$, pp.384-395.

Akin J.E. and Mofid M. (1989): Numerical solution for response of beam with moving masses. - Journal of Structural Engineering, vol.115, No.1.

Akpobi J.A. and Nkenwokeneme E.U. (2009): Finite element analysis of transverse vibrating of Euler-Bernoulli beams on elastic foundation. - Journal of Mathematical Association of Nigeria, vol.36, No.2, pp.06-21.

Bolotin V. (1961): Problem of bridge vibration under the action of a moving load. - Izvestiya an USSR, Mechanika 1 Mashinostroenie, vol.4, pp.104-105.

Chonany S. (1984): Dynamic response of a pre-stressed orthotropic thick strip to a moving line load. - Journal of Sound and Vibration, vol.93, No.3, pp.427-438.

Dada M.S. (2003): Transverse vibration of Euler-Bernoulli beams on elastic foundation under mobile distributed masses. - Journal of the Nigerian Association of Mathematical Physics, NSI 7, pp.225-233.

Dowell E.H. (1974): Dynamic analysis of elastic plate on a thin elastic foundation. - Journal of Sound and Vibration, vol.35, pp.345-360.

Dugush Y.A. and Eisenberger M. (2002): Vibration of non-uniform continuous beams under moving loads. - Journal of Sound and Vibration, pp.911-927.

Esmailzadeh E. and Ghorashi M. (1995): Vibration analysis of beams traversal by uniform partially distributed moving masses. - Journal of Sound and Vibration, vol.184, pp.8-17.

Esmailzadeh E. and Ghorashi M. (1997): Vibration analysis of a Timoshenko beam subjected to a travelling mass. Journal of Sound and Vibration, vol.199, No.4, pp.615-627.

Fryba L. (1973): Vibration of solids and structures under moving loads. - ZAMM, vol.53, No.7, pp.502-503.

Gbadeyan J.A. and Oni S.T. (1992): Dynamic response to moving concentrated masses of elastic foundation. - Journal of Sound and Vibration, vol.154, No.2, pp.343-358.

Gbadeyan J.A. and Oni S.T. (1995): Dynamic behavior of beams and rectangular plates under moving loads. - Journal of Sound and Vibration, vol.182, No.5, pp.677-695.

Gbadeyan J.A., Abiala I.O. and Gbolagade A.W. (2002): On the dynamic response of beams subjected to uniform partially distributed moving masses. - Nigerian Journal of Mathematics and Applications, pp.123-135.

Gbadeyan J.A. and Dada M.S. (2007): The effect of linearly varying distributed moving loads on beams. - Journal of Engineering and Applied Sciences, vol.2, No.6, pp.1006-1011. 
Hillerborg A. (1951): Dynamic influences of smoothly running on simply supported girders. - Kungl. Tekn. Hogskolen, Stockholm.

Inglis C.E. (1934): A Mathematical Treatise on vibration in Railway Bridges. - Cambridge University Press, Cambridge, UK and Macmillan New York, 203pp.

Kolousek V. (1974): Dynamics of Civil Engineering Structures. Part 1. General problems. - $2^{\text {nd }}$ ed SNTL, Prague.

Krylov A.N. (1971): Dynamics of Civil Engineering Structures. Part 1: General problems. - Zed. SNTL, Prague.

Kwon Y.W. and Bang H. (1996): The finite element method using MATLAB. - CRC Press, Boea Raton New York, London \& Tokyo.

Lowan A.N. (1935): On transverse oscillations of beams under the action of moving variable loads. - Philosophical Magazine, vol.19, No.27, pp.708-715.

Michaltsos G.T., Sophianopoulos D. and Kounadis A.N. (1996): The effect of moving mass and other parameters on the dynamic response of a simply supported beam. - Journal of Sound and Vibration, vol.191, pp.357-362.

Michaltsos G.T. and Kounadis A.N. (2001): The effect of centripetal and Coriolis forces on the dynamic response of light bridges under moving loads. - Journal of Vibration and Control, vol.7, pp.315-326.

Newmark N.M. (1959): A method of computation for structural dynamics. - J. Eng. Mech; ASCE, pp.67-94.

Reddy J.N. (1993): An Introduction to the Finite Element Method. - $2^{\text {nd }}$ Ed. New York: Mc Grow -Hill.

Sadiku S. and Leipholz H.H.E. (1995): On the dynamic of elastic systems with moving concentrated masses. - Ingenieur Achiv., vol.57, pp.223-242.

Stanisic M.M. and Hardin J.C. (1968): On the response of beams to an arbitrary number of moving masses. - J. of the Franklin Institute, vol.287, pp.115-123.

Stokes G. (1883): Discussion of a differential equation relating to the breaking of railway bridges. - Transaction of the Cambridge Philaraphical Society, vol.8, No.5, pp.707-705.

Timoshenko S.P., Young D.H. and Weaver J.W. (1974): Vibration Problem in Engineering. - New York: Wiley.

Wills R. (1849): Experiment for determining the effect producing by causing weights to travel over bars with different velocities. In report of the commissioners appointed to inquire into the application of iron to railway structures.

Wu J.S. and Dai C.W. (1987): Dynamic response of multi-span non-uniform beams due to moving loads. - Journal of structural Engineering, vol.113, pp.458-474.

Zimmemnann H. (1896): Die Schwingungen Eines Tragers mit Bewegler Lasts. - Centrallblatt der Bauverwaltung, vol.16, No.23, pp.249-251.

Received: October 14, 2014

Revised: September 17, 2015 